\title{
Anxiety and Depression in Eosinophilic Esophagitis: A Scoping Review and Recommendations for Future Research
}

\section{Tiffany $\mathrm{H}$ Taft $\mathbb{D}^{\prime}$ \\ Livia Guadagnoli ${ }^{\prime}$ \\ Emily Edlynn ${ }^{2}$}

'Northwestern University Feinberg School of Medicine, Division of Gastroenterology \& Hepatology, Chicago, IL, USA; ${ }^{2}$ Oak Park Behavioral Medicine LLC, Oak Park, IL, USA
Correspondence: Tiffany H Taft Northwestern University Feinberg School of Medicine, Division of Gastroenterology \& Hepatology, 676 N. Saint Clair Street, Suite 1400, Chicago, IL 606I0, USA

$\mathrm{Tel}+\mid$ 3|2-725-6175

Email ttaft@northwestern.edu
This article was published in the following Dove Press journal: Journal of Asthma and Allergy

\begin{abstract}
Eosinophilic esophagitis (EoE) is a rapidly emerging chronic disease with limited treatments. Impacting both children and adults, EoE and its treatments have the potential to significantly reduce psychological functioning, including increasing anxiety and depression. In this paper, we provide a scoping review of the scientific literature on anxiety and depression in both pediatric and adult patients. We aim to document the current state of research, identify knowledge gaps, recognize unique challenges that EoE patients may face as they relate to psychosocial function, and offer suggestions for future research directions. Based on the current review, both adult and pediatric patients with EoE are at risk for anxiety and depression symptoms, both due to the disease process and the prevailing dietary treatments. Significant gaps exist in the current understanding of anxiety and depression in EoE, providing ample opportunity for future studies to address this important issue.
\end{abstract}

Keywords: eosinophilic esophagitis, anxiety, depression, quality of life, scoping review

\section{Introduction}

Eosinophilic gastrointestinal disorders (EGIDs) are immune-mediated chronic diseases with the potential to impact the entirety of the digestive system. ${ }^{1}$ The most commonly diagnosed EGID, eosinophilic esophagitis (EoE), is characterized by chronic infiltration of the esophagus by eosinophils, normally absent in esophageal tissues. The diagnostic cutoff for EoE is greater than 15 eosinophils per high power field retrieved by biopsy. The prevailing theory is eosinophilic infiltration is due to exposure to environmental antigens, typically in foods, that triggers the allergic response. Structural changes may occur, including the presence of esophageal rings, furrows, exudates, and stricture. ${ }^{2}$ The most common symptom of EoE in adult patients is dysphagia, or difficulty swallowing, that may lead to food impaction. Other symptoms include heartburn and chest pain, which are the most common symptoms in children along with failure to thrive and poor appetite. Treatments for EoE are limited to swallowed, topical corticosteroids and elimination diets., ${ }^{2,3}$

In addition to EoE, other EGIDs include eosinophilic gastritis (EG; impacting the stomach), eosinophilic gastroenteritis (EGE; impacting the stomach and small bowel) and eosinophilic colitis (EC; impacting the colon). ${ }^{4}$ These EGIDs are considered much rarer than EoE at the present time, and symptoms include nausea, vomiting, loss of appetite, abdominal pain, and diarrhea. Treatments are also limited to corticosteroids and dietary modification. 
Currently, EoE is estimated to impact 10 to 57 per 100,000 people globally, with increasing incidence and prevalence rates. ${ }^{5}$ The estimated cost of EoE approaches $\$ 1$ billion dollars annually, derived from outpatient visits, endoscopies, hospitalizations including emergency room visits, and medications. ${ }^{6}$ Additional costs are attributed to the need to follow special elimination diets, requiring patients to shop at specialty stores, or the use of expensive elemental formulas. Many patients are diagnosed with an EoE as a child, further adding to the extended burden of this disease.

As EoE has gained more attention in gastroenterology practice and research, the evaluation of their impact on mental well-being and health-related quality of life has also increased. However, significant gaps remain in the literature in our understanding of the relationships between EoE and these constructs, especially compared to other chronic digestive diseases such as inflammatory bowel disease $^{7,8}$ and irritable bowel syndrome. ${ }^{9}$ As such, we aim to review the existing literature as it relates to two specific mental health concerns in patients with EoE: anxiety and depression, in both pediatric and adult patient populations. We also aim to provide suggestions for future lines of inquiry in anxiety and depression in EoE, as well as other potential aspects of mental health that may be impacted by these diseases.

\section{Methods}

A scoping review of studies published through July 2019 (no start date) in which participants had a diagnosis of at least one EGID type was performed via the online databases PubMed, PsycINFO, and Google Scholar following PRISMA guidelines (Figure 1).

\section{Inclusion Criteria}

We included all studies that met the following criteria: a) published in English in a peer-reviewed journal, b) participants were diagnosed with at least one EGID, and c) anxiety and/or depression was evaluated using standardized assessment tools. Studies that measured healthrelated quality of life were evaluated and included if anxiety or depression was part of the HRQOL assessment tool utilized.

\section{Procedures}

Articles were identified and stored in an EndNote database. Titles or abstracts were returned via the following keyword search combinations: eosinophilic gastrointestinal disorders, eosinophilic esophagitis, eosinophilic gastritis, eosinophilic gastroenteritis, eosinophilic colitis, anxiety, depression, psychosocial, psychological, mental health. Each unique abstract was examined by two raters (TT, LG) for inclusion criteria and any that were explicitly unmet (e.g., study of nonhumans, no mention of anxiety or depression) were discarded. Inter-rater agreement was $100 \%$. Reference lists of identified articles and book chapters were also reviewed for additional studies. Unpublished manuscripts, case reports, and dissertations are not included.

The majority of studies were published in the United States and Switzerland. Both adult and child/adolescent studies are included in this review and the findings are organized adult and pediatric studies. To date, no research evaluates anxiety and depression in non-EoE EGIDs. As such, this review is limited to EoE.

\section{Adult Patients with EoE General Findings}

The literature search yielded only a handful of studies directly measuring anxiety or depression in adult EoE patients. Often times, anxiety and depression are included in studies evaluating other constructs such as HRQOL, social interactions, and disease stigmatization. As such, reviews of these patient outcomes are included within the context of how they are associated with anxiety and depression.

\section{Anxiety and Depression}

Few studies have evaluated the prevalence and impact of anxiety or depression in adult patients with EoE (Tables 1 and 2). A 2019 study sought to characterize a cohort of adult EoE patients through a retrospective medical record review, which included assessing the prevalence of several psychiatric comorbidities using ICD-9 and ICD-10 codes. ${ }^{10}$ Overall, $31 \%$ of patients had at least one psychiatric or neuropsychiatric comorbidity, with $12 \%$ of the sample demonstrating a diagnosis of depression, followed by anxiety, which was reported by $9.3 \%$ of patients. Further, the authors found these rates were significantly higher than the general hospital population, although comparable to the natural history of each respective disorder. ${ }^{10}$ Another study applied the Hospital Anxiety and Depression Scale-8 (HADS-8) to a cohort of Spanish patients with EoE. Results demonstrated that $31.1 \%$ and $9.8 \%$ reported anxiety and depression in the "probable-certain" range (score $>8$ ), respectively. ${ }^{11}$ These 


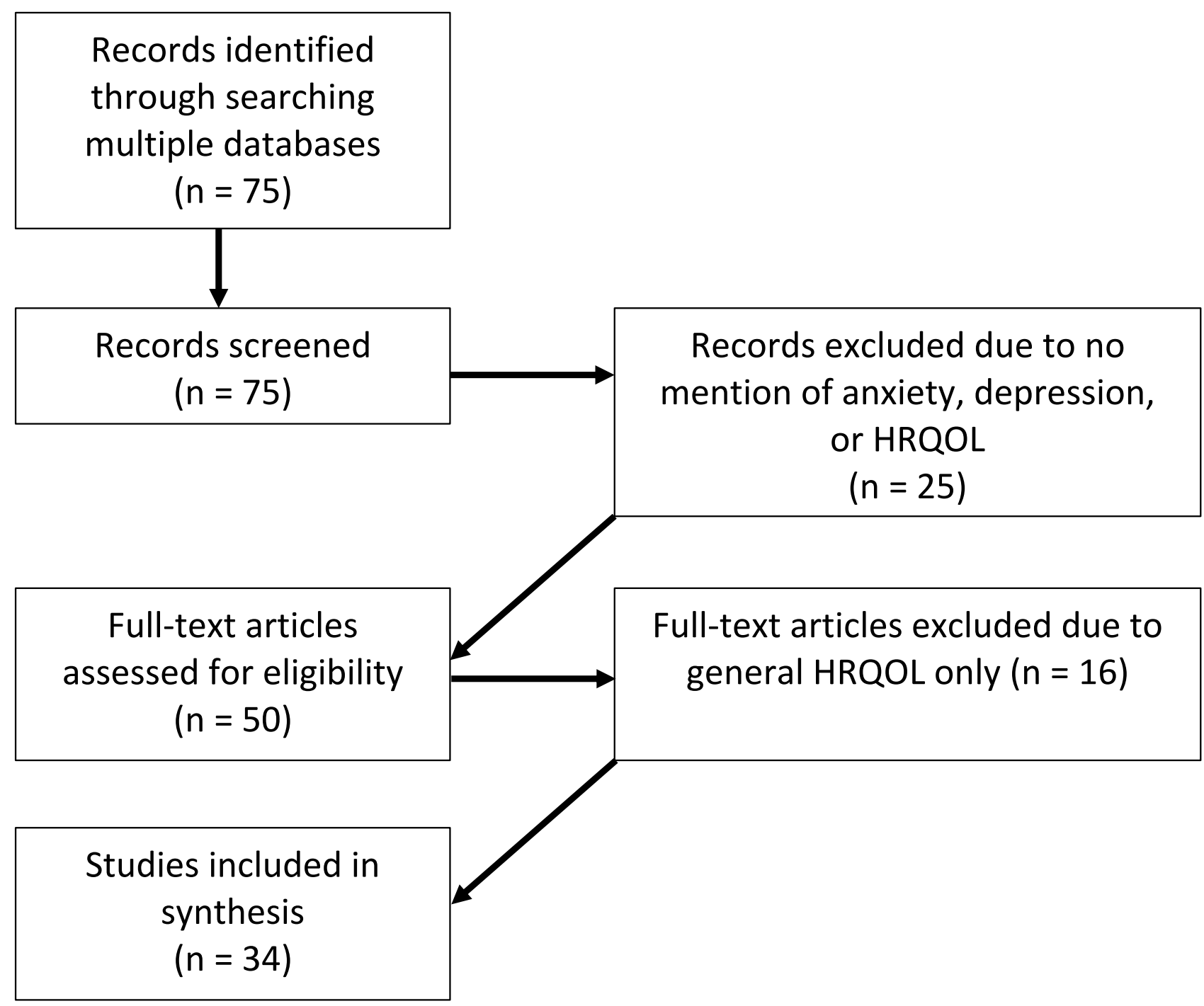

Figure I PRISMA diagram for selection of sources of evidence.

findings remained relatively stable at the 12 -week re-test period.

Research suggests potential sex differences in adult patients with EoE, specifically with women reporting increased symptoms of anxiety and depression compared to men. ${ }^{12}$ These findings are consistent with research in the general population. ${ }^{13-15}$ However, more research is warranted before conclusive statements can be made.

\section{Illness Stigma}

Illness stigma may also impact anxiety and depression in adult patients with EoE. Greater internalized and perceived illness stigma was found to be significantly associated with increased anxiety and depression symptoms. ${ }^{12,16}$ Further, perceived and internalized stigma were each significant predictors of both anxiety and depression, even when controlling for variables such as disease severity, duration, and gender. $^{12,16}$

\section{Psychological Impact of EoE Treatment}

There are several options for EoE treatment, including pharmacological therapy, procedural intervention (e.g. balloon distention), and dietary modification, all of which have the potential of impacting an individual's psychosocial functioning. In terms of medication, patients with EoE may report fear or worry about potential side effects, ${ }^{17}$ which can exacerbate an already stressful disease experience. Patients using dietary therapy may also experience negative impacts on their psychosocial functioning, in some cases even more so than those exclusively using medications. ${ }^{18}$ Dietary therapy requires adherence, which can be burdensome and inconvenient, ${ }^{17,19}$ and has been 
Table I Relevant Studies Examining Depression in Adults with EoE

\begin{tabular}{|c|c|c|c|c|c|c|}
\hline & Author Group & Year & Study Design & $\begin{array}{l}\text { Sample } \\
\text { Size }\end{array}$ & $\begin{array}{l}\text { Assessments } \\
\text { Used }\end{array}$ & Estimates Obtained \\
\hline 1 & Leigh and Spergel $^{10}$ & 2019 & $\begin{array}{l}\text { Retrospective Chart } \\
\text { Review }\end{array}$ & 34 & ICD-9/ICD- 10 code & I $2 \%$ Had diagnosis of Depression. \\
\hline 2 & Wang et al $^{19}$ & 2018 & Cross-sectional & 42 & $\begin{array}{l}\text { NIH-PROMIS } \\
\text { Depression Scale }\end{array}$ & $\begin{array}{l}\text { Depression scores higher in former users of } \\
\text { SFED compared to current users. }\end{array}$ \\
\hline 3 & Taft et $\mathrm{al}^{26}$ & 2011 & Scale Development & 201 & EoE-QOL-A & $\begin{array}{l}\text { Emotional Impact is a subscale on EoE- } \\
\text { specific measure of QOL. }\end{array}$ \\
\hline 4 & Lucendo et al" & 2014 & Cross-sectional & 170 & $\begin{array}{l}\text { Hospital Anxiety \& } \\
\text { Depression Scale }\end{array}$ & $9.8 \%$ Scored above cutoff for depression. \\
\hline 5 & Guadagnoli and Taft ${ }^{12}$ & 2019 & Cross-sectional & 149 & $\begin{array}{l}\text { NIH-PROMIS } \\
\text { Depression Scale }\end{array}$ & $\begin{array}{l}\text { Stigma internalization is positively correlated } \\
\text { with increased depression. }\end{array}$ \\
\hline 6 & Guadagnoli et al $^{16}$ & 2017 & Cross-sectional & 149 & $\begin{array}{l}\text { NIH-PROMIS } \\
\text { Depression Scale }\end{array}$ & $\begin{array}{l}\text { Stigma perception is positively correlated } \\
\text { with increased depression. }\end{array}$ \\
\hline
\end{tabular}

found to negatively impact the emotional aspects of HRQOL in adult patients with EoE. ${ }^{20}$ Further, research has found that diet-related anxiety, such as worry about food being unavailable and time required to prepare foods, is associated with decreased dietary adherence for adult patients on the six-food elimination diet. ${ }^{19}$ In addition, anxiety and depression levels appear to be higher in patients identified as former users of the six-food elimination diet, compared to those who are actively using the diet, suggesting a relationship between emotional distress and dietary use, although directionality cannot be concluded. ${ }^{19}$

\section{Social Impacts of EoE}

Finally, EoE may impact patients' social experience, which can in turn, affect emotional well-being. Patients with EoE report experiencing social embarrassment or distress due to their diagnosis, including negative experiences dining out or attending work interviews, worry about having a choking episode in public, and concern about having to hide the attack from others. ${ }^{17}$ Embarrassment and shame may contribute to perceived or internalized illness stigma, which can also negatively affect anxiety and depression symptoms in patients with EoE. ${ }^{12,16}$

Interestingly, despite these findings, patients typically endorse feeling open to disclosing their illness to friends and family. ${ }^{17}$ The benefits of social support have been studied in a variety of chronic illnesses and are established as an important protective factor for prevention of adverse mental health outcomes and promotion of positive health behaviors. $^{21,22}$ Thus, encouraging discussion about EoE and cultivating support from friends and family may aid as a buffer the potentially harmful outcomes.

\section{Relationship with HRQOL}

While literature on anxiety and depression in adult patients with EoE is scarce, there has been progress in the field evaluating the impact of EoE on health-related quality of life (HRQOL). Research has consistently found that EoE patients experience reduced HRQOL, due to several facets of their disease, which has resulted in psychological and social implications. ${ }^{18,20,23,24}$ Notably, adult patients with EoE view HRQOL as one of the most important outcomes in long and short-term therapy, even when compared to reduction in biological and histological activity, ${ }^{25}$ underscoring HRQOL as an important facet of the overall EoE patient experience.

The demand for a better understanding of the impact of EoE on psychosocial functioning was augmented by the development of the Adult Eosinophilic Esophagitis Quality of Life (EoE-QOL-A) questionnaire, a tool to assess HRQOL specific to the EoE population. ${ }^{26}$ In addition to a total score, the EoE-QOL-A is comprised of several subscales, including emotional impact, social impact, eating/diet impact, choking anxiety, and disease anxiety, all of which have individual subscale scores, which allows for identification of specific underlying issues patients may be experiencing.

The emotional impact and choking and disease anxiety subscales are of particular interest, as it evaluates aspects 
Table 2 Relevant Studies Examining Anxiety in Adults with EoE

\begin{tabular}{|c|c|c|c|c|c|c|}
\hline & Author Group & Year & Study Design & $\begin{array}{l}\text { Sample } \\
\text { Size }\end{array}$ & Assessments Used & Estimates Obtained \\
\hline 1 & Wang et al ${ }^{19}$ & 2018 & Cross-sectional & 42 & $\begin{array}{l}\text { NIH-PROMIS Anxiety } \\
\text { Scale }\end{array}$ & $\begin{array}{l}\text { Diet-related anxiety may impact SFED } \\
\text { adherence; Anxiety higher in former users } \\
\text { of SFED compared to current users. }\end{array}$ \\
\hline 2 & Stern et al ${ }^{18}$ & 2018 & Prospective & 167 & EoE-QOL-A & $\begin{array}{l}\text { Anxiety (measured under QOL), is } \\
\text { associated with symptom severity but not } \\
\text { endoscopy or histology results. Prior food } \\
\text { impaction influences choking anxiety. }\end{array}$ \\
\hline 3 & Safroneeva et $\mathrm{al}^{2}$ & 2018 & Cross-sectional & 109 & EoE-QOL-A & $\begin{array}{l}\text { Anxiety (measured under QOL) is } \\
\text { associated with patient treatment goals. }\end{array}$ \\
\hline 4 & Lucendo et $\mathrm{al}^{20}$ & 2018 & Cross-sectional & 170 & EoE-QOL-A & $\begin{array}{l}\text { Disease anxiety and choking anxiety were } \\
\text { the highest scoring domains of QOL. }\end{array}$ \\
\hline 5 & Taft et al ${ }^{17}$ & 2011 & Qualitative & 24 & $\begin{array}{l}\text { Semi-Structured } \\
\text { Interview }\end{array}$ & $\begin{array}{l}\text { Disease anxiety and choking anxiety are } \\
\text { important aspects of QOL. }\end{array}$ \\
\hline 6 & Taft et $\mathrm{al}^{26}$ & 2011 & Scale development & 201 & EoE-QOL-A & $\begin{array}{l}\text { Disease anxiety and choking anxiety are } 2 \\
\text { subscales on EoE-specific measure of QOL. }\end{array}$ \\
\hline 7 & Lucendo et al" & 2014 & Prospective & 170 & $\begin{array}{l}\text { Hospital Anxiety and } \\
\text { Depression Scale }\end{array}$ & $\begin{array}{l}31.1 \% \text { of patients scored above the cutoff } \\
\text { for anxiety. }\end{array}$ \\
\hline 8 & Guadagnoli and Taft ${ }^{12}$ & 2019 & Cross-sectional & 149 & $\begin{array}{l}\text { NIH-PROMIS Anxiety } \\
\text { Scale }\end{array}$ & $\begin{array}{l}\text { Stigma internalization is positively } \\
\text { correlated with increased anxiety. }\end{array}$ \\
\hline 9 & Guadagnoli et $\mathrm{al}^{16}$ & 2017 & Cross-sectional & 149 & $\begin{array}{l}\text { NIH-PROMIS Anxiety } \\
\text { Scale }\end{array}$ & $\begin{array}{l}\text { Stigma perception is positively correlated } \\
\text { with increased anxiety. }\end{array}$ \\
\hline 10 & Leigh and Spergel ${ }^{10}$ & 2019 & $\begin{array}{l}\text { Retrospective chart } \\
\text { review }\end{array}$ & 34 & ICD-9/ICD-10 & 9.3\% Had diagnosis of anxiety. \\
\hline II & Safroneeva et a $\left.\right|^{48}$ & 2018 & Cross-sectional & 98 & EoE-QOL-A & $\begin{array}{l}\text { Symptoms severity was correlated with } \\
\text { HRQOL scale and predicted HRQOL } \\
\text { scores, including anxiety. }\end{array}$ \\
\hline
\end{tabular}

of anxiety and depression within HRQOL. The emotional impact subscale assesses the degree to which patients have felt like life is less enjoyable or felt helpless or isolated because of EoE, and was found to have the greatest influence on decreased HRQOL in a sample of patients with EoE in a recent study. ${ }^{18}$

The disease anxiety and choking anxiety subscales are also important contributors to HRQOL in adult EoE patients. ${ }^{17}$ In fact, a separate study found that disease anxiety and choking anxiety had the largest impacts on overall HRQOL in the EoE population. ${ }^{11,20}$ EoE symptoms, such as dysphagia or food impaction, can produce a significant amount of fear and concern for patients, ${ }^{17,18}$ and increased symptom severity is a significant predictor of both disease and choking anxiety. ${ }^{27}$ Further underscoring the association between emotional distress and HRQOL is the finding that increased scores on more general measures of anxiety and depression are significantly associated with decreases in HRQOL (as measured by the EoE-QOL-A) ${ }^{11,26}$ However, some research suggests the correlation between anxiety and HRQOL is stronger than the relationship between HRQOL and depression. ${ }^{11}$

\section{Limitations and Future Research for Adults with EoE}

There is limited understanding of the role of anxiety and depression in adult patients with EoE. To our knowledge, there is one qualitative study evaluating these constructs, and while there is an increasing number of quantitative studies, the research is generally lacking in rigor and efficacy. 
No prospective studies exist that are specifically aimed to evaluate clinical anxiety and/or depression in patients with EoE. In terms of prevalence, one study exists reporting the prevalence of anxiety and depression diagnoses in the adult EoE population. ${ }^{10}$ While this helpful on a broad level, given the nature of retrospective reviews, we cannot confirm the accuracy of the diagnostic codes. For example, patients may be in remission for their psychiatric disorder but still have an active ICD code, or diagnoses may have been determined without appropriate psycho-diagnostic evaluation. Thus, results should be interpreted with caution.

A few studies applied self-reported measures of anxiety and depression, such as the PROMIS Anxiety, PROMIS Depression, and Hospital Anxiety and Depression Scale (HADS). These scales are particularly useful in screening to understand the magnitude and direction of anxious or depressive symptoms. However, they are not sufficient in diagnosing a clinical level of anxiety or depression, which would require an additional evaluation by a certified mental health professional. ${ }^{28}$ In addition, several of these studies included anxiety and depression as secondary outcomes, resulting in lack of emphasis on the findings. Thus, future research should prioritize evaluating anxiety and/or depression as main outcomes, as further investigate the relationship between these constructs and other relevant clinical and psychosocial information.

The overwhelming majority of research in adult patients with EoE uses HRQOL scales (i.e. EoE -QOL -A) that include anxiety or emotional-related subscales, to assess for anxiety and depression symptoms. These studies capture the impact of EoE-specific anxiety and emotional distress, as compared to anxiety and depression as a general mental health concern (such as in the studies discussed above), which are viewed and assessed as different constructs. For example, a patient may not endorse general anxiety and worry in his or her everyday life but may experience disease or choking anxiety. Both constructs are important to consider in this population and could possibly produce different outcomes. While clinical anxiety and depression may result in an enhanced characterization of the EoE population, EoE-specific anxiety and depression can identify the more nuanced and potentially clinically relevant associations. Thus, future research should continue to pursue EoE-specific distress, such as emotional impacts as well as disease and choking anxiety, and the influence it has on adult patients with EoE.

\section{Children and Adolescent Patients with EoE \\ General Findings}

As the prevalence of EoE appears to be quickly growing, ${ }^{29,30}$ a better understanding of the impact of EoE on quality of life in children becomes more critical. The existing literature establishes a link between EoE and poorer HRQOL, with symptoms and disease status directly correlating with lower HRQOL. ${ }^{31,32}$ Within the larger body of research on HRQOL in EoE, evidence points to greater emotional and behavioral problems and worsened adjustment as children get older. ${ }^{33}$ Based on the scant studies of emotional symptoms within HRQOL, diseasespecific symptoms such as epigastric pain and certain treatment options (e.g., food restrictions and g-tubes) may be most predictive of emotional symptoms. ${ }^{33,34}$

In examining anxiety and depression specifically, however, the research is limited. Many studies of pediatric health-related quality of life collapse emotional symptoms on the PedsQL measure into one "psychosocial functioning" domain combined with school and social functioning, or include "worry" measured within the EoE module of the PedsQL. ${ }^{31,35}$

\section{Anxiety}

Studies examining anxiety specifically suggest that youth with EoE do have higher rates of anxiety symptoms compared to healthy populations ${ }^{29,33}$ (Table 3). In the study of 705 patients, $15.5 \%$ reported anxiety and depression, with $19 \%$ of older patients (11-17 years) endorsing these symptoms compared to $9.3 \%$ of younger patients $\left(<11\right.$ years). ${ }^{29}$ In a smaller cohort of 64 patients, reported rates of anxiety were $41 \%$ among children, but not stratified by age. ${ }^{33}$ These higher rates may be linked with symptoms and treatments unique to EoE, including worries about symptoms, ${ }^{36,37}$ dietary restrictions, and g-tubes. ${ }^{34,38}$ In the review by Klinnert et al clinical observations found patients with increased anxiety related to needing a G-tube and in those with comorbid food allergies which heightened fears about a lifethreatening reaction. Qualitative interviews corroborate these concerns with anxieties traversing food reactions and choices, and having endoscopies. ${ }^{36}$ The common intervention of dietary restriction likely increases worry about foods (by children and their caregivers), as well as fears of embarrassment in social situations. ${ }^{34,39}$ The specific symptoms most often identified include worry about disease and symptoms, physical symptoms of anxiety and autonomic arousal, ${ }^{40,41}$ and school avoidance. ${ }^{41}$ It should be noted that 
Table 3 Relevant Studies Examining Anxiety in Children/Adolescents with EoE

\begin{tabular}{|c|c|c|c|c|c|c|}
\hline & Author Group & Year & Study Design & $\begin{array}{l}\text { Sample } \\
\text { Size }\end{array}$ & Assessments Used & Estimates Obtained \\
\hline 1 & Jose et $\mathrm{al}^{41}$ & 2016 & $\begin{array}{l}\text { Cross-sectional } \\
\text { (Abstract) }\end{array}$ & 8 & $\begin{array}{l}\text { Screen for Child Anxiety- } \\
\text { Related Disorders }\end{array}$ & $38 \%$ Met criteria for anxiety. \\
\hline 2 & Harris et $\mathrm{al}^{33}$ & 2013 & $\begin{array}{l}\text { Retrospective } \\
\text { chartrReview }\end{array}$ & 64 & $\begin{array}{l}\text { I-hr Pediatric Behavioral } \\
\text { Health Assessment }\end{array}$ & $\begin{array}{l}41 \% \text { Reported anxiety, anxiety symptoms } \\
\text { increased with age. }\end{array}$ \\
\hline 3 & Franciosi et $\mathrm{al}^{36}$ & 2012 & Qualitative & 42 & $\begin{array}{l}\text { Semi-Structured } \\
\text { Interview }\end{array}$ & $\begin{array}{l}\text { Worry about symptoms and EoE were } \\
\text { specific themes. }\end{array}$ \\
\hline 4 & Cortina et $\mathrm{al}^{40}$ & 2010 & Cross-sectional & 108 & $\begin{array}{l}\text { Multidimensional Anxiety } \\
\text { Scale for Children }\end{array}$ & $\begin{array}{l}\text { Compared to healthy controls, children and } \\
\text { adolescents with EOE reported more } \\
\text { physical symptoms of anxiety and } \\
\text { autonomic arousal. }\end{array}$ \\
\hline 5 & Case et $\mathrm{al}^{38}$ & 2017 & Cross-sectional & $\begin{array}{l}46 \\
\text { families }\end{array}$ & $\begin{array}{l}\text { Revised Children's } \\
\text { Anxiety and Depression } \\
\text { Scale, Pediatric Quality of } \\
\text { Life Scale for EoE }\end{array}$ & $\begin{array}{l}50 \% \text { of participants reported high frequency } \\
\text { worry related to special diets, measured by } \\
\text { PedsQL-EoE Feelings subscale. }\end{array}$ \\
\hline 6 & Chehade et $\mathrm{al}^{29}$ & 2018 & Prospective & 705 & $\begin{array}{l}\text { Self-Reported History of } \\
\text { Anxiety or Depression }\end{array}$ & $\begin{array}{l}24.0 \% \text { in subjects } \geq 18 \text { years of age, } 9.0 \% \text { in } \\
\text { those } 11-17 \text { years of age, } 9.3 \% \text { in children } \\
<11 \text { years of age. }\end{array}$ \\
\hline 7 & Jose et $\mathrm{al}^{41}$ & 2017 & Cross-sectional & 20 & $\begin{array}{l}\text { Screen for Child Anxiety- } \\
\text { Related Disorders }\end{array}$ & $\begin{array}{l}\text { Caregivers of children with EoE report } \\
\text { more symptoms of anxiety disorder, panic } \\
\text { disorder, and school avoidance; compared } \\
\text { to general population. }\end{array}$ \\
\hline 8 & Lynch et $\mathrm{al}^{35}$ & 2018 & Review & & N/A & $\begin{array}{l}\text { Higher rates of anxious symptoms in youth } \\
\text { with EoE are associated with sleep problems } \\
\text { and pain, all of which impact HRQOL (no } \\
\text { study has yet examined these four } \\
\text { constructs at once). }\end{array}$ \\
\hline 9 & Lynch et $\mathrm{a}^{43}$ & 2017 & Cross-sectional & 50 & $\begin{array}{l}\text { Pediatric Quality of Life } \\
\text { Scale for EoE }\end{array}$ & $\begin{array}{l}\text { Caregiver reports rated children with EoE } \\
\text { and persistent pain as having more anxiety } \\
\text { symptoms compared to controls. }\end{array}$ \\
\hline
\end{tabular}

a majority of studies including anxiety as a variable discuss anxiety at the symptom level rather than representing actual anxiety disorders. Some evidence shows that anxiety symptoms increase with age, ${ }^{33}$ suggesting the importance of developmental considerations.

\section{Depression}

Although anxiety has received more attention than depression in studying emotional symptoms in children and adolescents with EoE, results of studies to date suggest that mood is an important area in which to increase understanding (Table 4). When measured with anxiety symptoms, some evidence shows depression may also increase with age at higher rates than the general population. ${ }^{29}$
Depressive symptoms have been found to contribute to medical non-adherence in youth with EoE, ${ }^{42}$ and to be related to persistent epigastric pain and greater sleep disturbance. ${ }^{43}$ In one study, children and adolescents with EoE reported more symptoms on subscales of anhedonia, negative mood, and negative self-esteem compared to healthy controls. ${ }^{40}$ This early evidence base justifies depression and depressive symptoms as an important component of studying HRQOL in pediatric EoE.

\section{Limitations and Suggestions for Future Research for Children with EoE}

Data from the limited research of anxiety and depression in pediatric EoE populations indicate this area needs 
Table 4 Relevant Studies Examining Depression in Children/Adolescents with EoE

\begin{tabular}{|c|c|c|c|c|c|c|}
\hline & Author Group & Year & Study Design & Sample Size & Assessments Used & Estimates Obtained \\
\hline I & Chehade et $\mathrm{al}^{29}$ & 2018 & Cross-sectional & 705 & $\begin{array}{l}\text { Self-Reported History } \\
\text { of Anxiety or } \\
\text { Depression }\end{array}$ & $\begin{array}{l}24.0 \% \text { in subjects } \geq 18 \text { years of age, } 9.0 \% \\
\text { in those } 11-17 \text { years of age, } 9.3 \% \text { in } \\
\text { children }<11 \text { years of age }\end{array}$ \\
\hline 2 & Hommel et $\mathrm{al}^{42}$ & 2012 & Cross-sectional & 96 & $\begin{array}{l}\text { Behavior Assessment } \\
\text { System for Children, } \\
\text { 2nd Edition }\end{array}$ & $\begin{array}{l}\text { Depressed patients being more likely } \\
(\mathrm{OR}=7.27) \text { to be non-adherent than non- } \\
\text { depressed patients }\end{array}$ \\
\hline 3 & Lynch et $\mathrm{al}^{35}$ & 2018 & Cross-sectional & 50 & $\begin{array}{l}\text { Pediatric Quality of Life } \\
\text { Scale for EoE }\end{array}$ & $\begin{array}{l}\text { Caregivers of children with EoE and } \\
\text { persistent pain reported significantly more } \\
\text { depressive symptoms in their children } \\
\text { compared to healthy controls }\end{array}$ \\
\hline 4 & Case et $\mathrm{a}^{38}$ & 2017 & Cross-sectional & 20 & $\begin{array}{l}\text { Revised Children's } \\
\text { Anxiety and Depression } \\
\text { Scale, Pediatric Quality } \\
\text { of Life Scale for EoE }\end{array}$ & $\begin{array}{l}50 \% \text { of participants reported high } \\
\text { frequency anger and sadness related to } \\
\text { special diets, measured by PedsQL-EoE } \\
\text { Feelings subscale }\end{array}$ \\
\hline 5 & Cortina et $\mathrm{al}^{40}$ & 2010 & Cross-sectional & $\begin{array}{l}\text { I08 (Mothers \& } \\
\text { Children) }\end{array}$ & $\begin{array}{l}\text { Children's Depression } \\
\text { Inventory }\end{array}$ & $\begin{array}{l}\text { Children and adolescents with EoE } \\
\text { reported greater overall depressive } \\
\text { symptoms compared to controls, and more } \\
\text { symptoms on three subscales: anhedonia, } \\
\text { negative mood, negative self-esteem }\end{array}$ \\
\hline 6 & Lynch et $\mathrm{al}^{43}$ & 2018 & Review & & & $\begin{array}{l}\text { Higher rates of depressive symptoms in } \\
\text { youth with EoE are associated with sleep } \\
\text { problems and pain, all of which impact } \\
\text { HRQOL (no study has yet examined } \\
\text { these four constructs at once) }\end{array}$ \\
\hline
\end{tabular}

further study to provide better understanding of the role of psychological symptoms across the developmental continuum of life with EoE, and to inform more holistic treatment interventions. Future research should more systematically not only include depression and anxiety as constructs, but should develop a more consistent approach to conceptualization and measurement.

Associations between factors such as internalizing symptoms, sleep disturbance, and pain warrant more analysis. An improved understanding of how these symptoms interrelate would inform more effective clinical interventions, including behavioral health treatments potentially targeting pain and sleep in order to decrease internalizing symptoms.

Finally, caregiver anxiety has been shown to be elevated, especially for those of younger children, due to worries about growth, nutrition, and avoiding harmful foods. ${ }^{34}$ As parent anxiety is known to increase the risk of child anxiety, this potential association also deserves more research in pediatric EoE. Screening for caregiver anxiety and providing appropriate referrals such as behavioral health interventions for caregivers could be an important part of treatment for pediatric EoE.

\section{Conclusions}

This scoping review of anxiety and depression studies in pediatric and adult patients with EoE demonstrates a significant gap in the existing literature and the necessity of more research to understand the true impacts of these mental health co-morbidities on patient outcomes. However, we can conclude that EoE does increase the risk of developing symptoms of anxiety and depression, which in turn may reduce HRQOL and treatment adherence. The lack of treatment options may be a driver of anxiety, especially in those patients who need to follow strict elimination diets indefinitely. Impacts on eating and food-specific anxieties are legitimate concerns that treating physicians and dietitians should actively monitor, including screening for restrictive behaviors beyond what would be considered reasonable (i.e. Avoidant Restrictive 
Table 5 Common Screening Tools for Anxiety and Depression

\begin{tabular}{|c|c|c|c|}
\hline Measure Title & Anxiety & Depression & Number of Items \\
\hline \multicolumn{4}{|l|}{ Adults 18 years+ } \\
\hline Hospital Anxiety and Depression Scale (HADS) & $\checkmark$ & $\checkmark$ & 8 \\
\hline Generalized Anxiety Disorder - 7 (GAD-7) & $\checkmark$ & & 7 \\
\hline Patient Health Questionnaire - 9 (PHQ-9) & & $\checkmark$ & 9 \\
\hline NIH-PROMIS Mental Health - Anxiety & $\checkmark$ & & 7 \\
\hline NIH-PROMIS Mental Heath - Depression & & $\checkmark$ & 8 \\
\hline Kessler 10 & $\checkmark$ & $\checkmark$ & 14 \\
\hline \multicolumn{4}{|l|}{ Children 17 years or Younger } \\
\hline Patient Health Questionnaire for Adolescents (PHQ-A) & & $\checkmark$ & 9 \\
\hline Mood \& Feelings Questionnaire - Short Form (MFQ-SF) & $\checkmark$ & & 13 \\
\hline Childhood Anxiety Sensitivity Index (ASI) & & $\checkmark$ & 16 \\
\hline Screen for Child Anxiety-Related Disorders (SCARED) ${ }^{a}$ & & $\checkmark$ & 41 \\
\hline
\end{tabular}

Note: ${ }^{a}$ Completed by parent.

Food Intake Disorder (ARFID)). ${ }^{44}$ ARFID is a condition defined by the Diagnostic and Statistical Manual for Mental Disorders - Fifth dition,generally applied to feeding issues in children. Recently ARFID specific to coping with digestive diseases has become a growing area of attention, including a 2019 case report of two children with EoE. ${ }^{45}$

We recommend gastroenterologists who treat EoE, and other EGIDs for that matter, conduct routine screens for anxiety and depression. There are several brief measures easily implemented in clinical practice such as the PROMIS mental health scales, the PHQ-9, and the GAD-7 (Table 5). In addition to screening, referral lines to mental health professionals specializing in health psychology, behavioral medicine, or psycho-gastroenterology should be established so patients can be provided with resources once anxiety or depression symptoms are identified. Effective psychological interventions for anxiety and depression, such as cognitive behavioral therapy or acceptance and commitment therapy, while not formally evaluated in EoE, have been tested in other chronic digestive diseases and demonstrate sufficient efficacy. ${ }^{46,47}$

\section{Disclosure}

The authors report no conflicts of interest in this work.

\section{References}

1. Schoepfer A, Blanchard C, Dawson H, et al. Eosinophilic esophagitis: latest insights from diagnosis to therapy. Ann $N$ Y Acad Sci. 2018;1434:84-93. doi:10.1111/nyas.2018.1434.issue-1

2. Safroneeva E, Saner C, Rossel JB, et al. Cohort profile: the Swiss Eosinophilic Esophagitis Cohort Study (SEECS). Inflamm Intest Dis. 2018;2:163-170. doi:10.1159/000486131
3. Schoepfer AM, Straumann A, Safroneeva E. Pharmacologic treatment of eosinophilic esophagitis: an update. Gastrointest Endosc Clin N Am. 2018;28:77-88. doi:10.1016/j.giec.2017.07.007

4. Pesek $\mathrm{RD}$, Reed $\mathrm{CC}$, Muir $\mathrm{AB}$, et al. Increasing rates of diagnosis, substantial co-occurrence, and variable treatment patterns of eosinophilic gastritis, gastroenteritis, and colitis based on 10-year data across a multicenter consortium. Am J Gastroenterol. 2019;114:984-994. doi: $10.14309 /$ ajg. 0000000000000228

5. Moawad FJ. Eosinophilic esophagitis: incidence and prevalence. Gastrointest Endosc Clin N Am. 2018;28:15-25. doi:10.1016/j. giec.2017.07.001

6. Dellon ES. Cost-effective care in eosinophilic esophagitis. Ann Allergy Asthma Immunol. 2019;123:166-172. doi:10.1016/j.anai.2019.04.010

7. Stapersma L, van den Brink G, Szigethy EM, et al. Systematic review with meta-analysis: anxiety and depression in children and adolescents with inflammatory bowel disease. Aliment Pharmacol Ther. 2018;48:496-506.

8. Neuendorf R, Harding A, Stello N, et al. Depression and anxiety in patients with Inflammatory bowel disease: a systematic review. J Psychosom Res. 2016;87:70-80. doi:10.1016/j.jpsychores.2016.06.001

9. Zamani M, Alizadeh-Tabari S, Zamani V. Systematic review with meta-analysis: the prevalence of anxiety and depression in patients with irritable bowel syndrome. Aliment Pharmacol Ther. 2019;50:132-143. doi:10.1111/apt.15325

10. Leigh LY, Spergel JM. An in-depth characterization of a large cohort of adult patients with eosinophilic esophagitis. Ann Allergy Asthma Immunol. 2019;122:65-72.e1. doi:10.1016/j.anai.2018.09.452

11. Lucendo AJ, Sanchez-Cazalilla M, Molina-Infante J, et al. Transcultural adaptation and validation of the "adult eosinophilic esophagitis quality of life questionnaire" into Spanish. Rev Esp Enferm Dig. 2014;106:386-394.

12. Guadagnoli L, Taft TH. Internalized stigma in patients with eosinophilic gastrointestinal disorders. J Clin Psychol Med Settings. 2019:1-10.

13. Salk RH, Hyde JS, Abramson LY. Gender differences in depression in representative national samples: meta-analyses of diagnoses and symptoms. Psychol Bull. 2017;143:783-822. doi:10.1037/bul0000102

14. Grenier S, Payette MC, Gunther B, et al. Association of age and gender with anxiety disorders in older adults: a systematic review and meta-analysis. Int J Geriatr Psychiatry. 2019;34:397-407. doi:10.1002/ gps.5035

15. McLean CP, Asnaani A, Litz BT, et al. Gender differences in anxiety disorders: prevalence, course of illness, comorbidity and burden of illness. J Psychiatr Res. 2011;45:1027-1035. doi:10.1016/j.jpsychires.2011. 03.006 
16. Guadagnoli L, Taft TH, Keefer L. Stigma perceptions in patients with eosinophilic gastrointestinal disorders. Dis Esophagus. 2017;30:1-8. doi:10.1093/dote/dox014

17. Taft TH, Kern E, Keefer L, et al. Qualitative assessment of patient-reported outcomes in adults with eosinophilic esophagitis. J Clin Gastroenterol. 2011;45:769-774. doi:10.1097/MCG.0b013e3182166a5a

18. Stern E, Taft T, Zalewski A, et al. Prospective assessment of disease-specific quality of life in adults with eosinophilic esophagitis. Dis Esophagus. 2018;31(4):dox128.

19. Wang R, Hirano I, Doerfler B, et al. Assessing adherence and barriers to long-term elimination diet therapy in adults with eosinophilic esophagitis. Dig Dis Sci. 2018;63:1756-1762. doi:10.1007/s10620018-5045-0

20. Lucendo AJ, Arias-Gonzalez L, Molina-Infante J, et al. Determinant factors of quality of life in adult patients with eosinophilic esophagitis. United European Gastroenterol J. 2018;6:38-45. doi:10.1177/2050640617707095

21. Martire LM, Helgeson VS. Close relationships and the management of chronic illness: associations and interventions. Am Psychol. 2017;72:601-612. doi:10.1037/amp0000066

22. Kingod N, Cleal B, Wahlberg A, et al. Online peer-to-peer communities in the daily lives of people with chronic illness: a qualitative systematic review. Qual Health Res. 2017;27:89-99. doi:10.1177/ 1049732316680203

23. van Rhijn BD, Smout AJ, Bredenoord AJ. Disease duration determines health-related quality of life in adult eosinophilic esophagitis patients. Neurogastroenterol Motil. 2014;26:772-778. doi:10.1111/ nmo.2014.26.issue-6

24. Straumann A. Eosinophilic esophagitis: emerging therapies and future perspectives. Gastroenterol Clin North Am. 2014;43:385-394. doi:10.1016/j.gtc.2014.02.005

25. Safroneeva E, Balsiger L, Hafner D, et al. Adults with eosinophilic oesophagitis identify symptoms and quality of life as the most important outcomes. Aliment Pharmacol Ther. 2018;48:1082-1090. doi:10.1111/apt. 15000

26. Taft TH, Kern E, Kwiatek MA, et al. The adult eosinophilic oesophagitis quality of life questionnaire: a new measure of health-related quality of life. Aliment Pharmacol Ther. 2011;34:790-798. doi:10.1111/apt.2011.34.issue-7

27. Safroneeva E, Coslovsky M, Kuehni CE, et al. Eosinophilic oesophagitis: relationship of quality of life with clinical, endoscopic and histological activity. Aliment Pharmacol Ther. 2015;42:1000-1010.

28. Snaith RP. The hospital anxiety and depression scale. Health Qual Life Outcomes. 2003;1:29. doi:10.1186/1477-7525-1-29

29. Chehade M, Jones SM, Pesek RD, et al. Phenotypic characterization of eosinophilic esophagitis in a large multicenter patient population from the consortium for food allergy research. J Allergy Clin Immunol Pract. 2018;6:1534-1544 e5. doi:10.1016/j.jaip.2018.05.038

30. Cantu P, Penagini R. Eosinophilic oesophagitis: the essentials for daily practice. Scand J Gastroenterol. 2010;45:528-532. doi:10.3109/ 00365521003587788

31. Franciosi JP, Hommel KA, Bendo CB, et al. PedsQL eosinophilic esophagitis module: feasibility, reliability, and validity. $J$ Pediatr Gastroenterol Nutr. 2013;57:57-66. doi:10.1097/MPG.0b013e318 $28 \mathrm{flfd} 2$

32. Klinnert MD, Silveira L, Harris R, et al. Health-related quality of life over time in children with eosinophilic esophagitis and their families. J Pediatr Gastroenterol Nutr. 2014;59:308-316. doi:10.1097/ MPG.0000000000000451
33. Harris RF, Menard-Katcher C, Atkins D, et al. Psychosocial dysfunction in children and adolescents with eosinophilic esophagitis. J Pediatr Gastroenterol Nutr. 2013;57:500-505. doi:10.1097/ MPG.0b013e31829ce5ad

34. Klinnert MD. Psychological impact of eosinophilic esophagitis on children and families. Immunol Allergy Clin North Am. 2009;29:99107, x. doi:10.1016/j.iac.2008.09.011

35. Lynch MK, Barnes MJ, Dimmitt RA, et al. Disease-related predictors of health-related quality of life in youth with eosinophilic esophagitis. J Pediatr Psychol. 2018;43:464-471. doi:10.1093/jpepsy/jsx128

36. Franciosi JP, Hommel KA, DeBrosse CW, et al. Quality of life in paediatric eosinophilic oesophagitis: what is important to patients? Child Care Health Dev. 2012;38:477-483. doi:10.1111/j.13652214.2011.01265.x

37. Franciosi JP, Hommel KA, Greenberg AB, et al. Development of the pediatric quality of life inventory eosinophilic esophagitis module items: qualitative methods. BMC Gastroenterol. 2012;12:135. doi:10.1186/1471-230X-12-135

38. Case C, Furuta GT, Atkins D, et al. Diet and stress in pediatric eosinophilic esophagitis. J Pediatr Gastroenterol Nutr. 2017;65:281-284. doi:10.1097/MPG.0000000000001481

39. Menard-Katcher C, Henry M, Furuta GT, et al. Significance of feeding dysfunction in eosinophilic esophagitis. World $J$ Gastroenterol. 2014;20:11019-11022. doi:10.3748/wjg.v20.i31.11019

40. Cortina S, McGraw K, Dealarcon A, et al. Psychological functioning of children and adolescents with eosinophil-associated gastrointestinal disorders. Child Health Care. 2010;39:266-278. doi:10.1080/ 02739615.2010.515927

41. Jose J, Virojanapa A, Lehman EB, et al. Parental perception of anxiety in children with eosinophilic esophagitis in a tertiary care center. Ann Allergy Asthma Immunol. 2017;119:382-383. doi:10.1016/j.anai.2017.07.025

42. Hommel KA, Franciosi JP, Gray WN, et al. Behavioral functioning and treatment adherence in pediatric eosinophilic gastrointestinal disorders. Pediatr Allergy Immunol. 2012;23:494-499. doi:10.1111/ pai.2012.23.issue-5

43. Lynch MK, Dimmitt RA, Goodin BR. Evidence of disturbed sleep in children with eosinophilic esophagitis and persistent epigastric pain. J Pediatr Psychol. 2018;43:331-341. doi:10.1093/jpepsy/jsx117

44. Zimmerman J, Fisher M. Avoidant/Restrictive Food Intake Disorder (ARFID). Curr Probl Pediatr Adolesc Health Care. 2017;47:95-103. doi:10.1016/j.cppeds.2017.02.005

45. Robson J, Laborda T, Fitzgerald S, et al. Avoidant/restrictive food intake disorder in diet-treated children with eosinophilic esophagitis. J Pediatr Gastroenterol Nutr. 2019;69:57-60. doi:10.1097/ MPG.0000000000002323

46. Radziwon CD, Lackner JM. Cognitive behavioral therapy for IBS: how useful, how often, and how does it work? Curr Gastroenterol Rep. 2017;19:49. doi:10.1007/s11894-017-0590-9

47. Mikocka-Walus A, Andrews JM, Bampton P. Cognitive Behavioral Therapy for IBD. Inflamm Bowel Dis. 2016;22:E5-6. doi:10.1097/ MIB.0000000000000672

48. Safroneeva E, Straumann A, Schoepfer AM. Latest insights on the relationship between symptoms and biologic findings in adults with eosinophilic esophagitis. Gastrointest Endosc Clin $N \mathrm{Am}$. 2018;28:35-45. doi:10.1016/j.giec.2017.08.001 


\section{Publish your work in this journal}

The Journal of Asthma and Allergy is an international, peer-reviewed open-access journal publishing original research, reports, editorials and commentaries on the following topics: Asthma; Pulmonary physiology; Asthma related clinical health; Clinical immunology and the immunological basis of disease; Pharmacological interventions and new therapies. The manuscript management system is completely online and includes a very quick and fair peer-review system, which is all easy to use. Visit http://www.dovepress.com/testimonials.php to read real quotes from published authors.

Submit your manuscript here: https://www.dovepress.com/journal-of-asthma-and-allergy-journal 